\title{
Principal Component and Cluster Analysis in Inbred Lines of Maize (Zea mays L.)
}

\author{
K. Mounika ${ }^{1 *}$, M. Lal Ahamed ${ }^{2}$ and Sk. Nafeez Umar $^{3}$
}

${ }^{1}$ Department of Genetics and Plant Breeding, Agricultural College, Bapatla, Acharya N G Ranga Agricultural University, Guntur, Andhra Pradesh, India

${ }^{2}$ Department of Molecular Biology and Biotechnology, APGC, Lam, Guntur, A.P. India

${ }^{3}$ Department of Statistics and Computer Applications, Agricultural College, Bapatla, Acharya

$N$ G Ranga Agricultural University, Guntur, Andhra Pradesh, India

*Corresponding author

\section{A B S T R A C T}

\begin{tabular}{|l|}
\hline Key w or d s \\
$\begin{array}{l}\text { Genetic divergence, } \\
\text { Hierarchical cluster } \\
\text { analysis, Maize, Principal } \\
\text { Component Analysis }\end{array}$ \\
\hline Article Info \\
\hline $\begin{array}{l}\text { Accepted: } \\
\text { 22 May 2018 } \\
\text { Available Online: } \\
\text { 10 June 2018 }\end{array}$ \\
\hline
\end{tabular}

In the present investigation a total of forty seven maize inbred lines were studied to assess the genetic diversity for 10 quantitative traits viz., days to $50 \%$ tasseling, days to $50 \%$ silking, days to maturity, plant height $(\mathrm{cm})$, ear length $(\mathrm{cm})$, ear height $(\mathrm{cm}), 100$-seed weight $(\mathrm{g})$, kernel rows per ear, number of kernels per row and grain yield per plant (g) using principal component analysis and hierarchical cluster analysis. The PCA identified four principal components (PCs) with Eigen value greater than 1.00 and accounted for 80.35 per cent of total variation. Cluster analysis based on Ward's minimum variance procedure distributed the inbreds into 7 clusters indicating their broad genetic base of which cluster II was the largest containing ten inbreds and maximum inter-cluster distance was recorded between clusters IV and VII (1177.88) suggesting their use in breeding programmes for the exploitation of heterosis for the desirable yield traits.

\section{Introduction}

Maize (Zea mays L.) is an important cereal crop of the family Poaceae belonging to the tribe Maydeae. The plant is native to South America and has chromosome number of $2 \mathrm{n}=20$. Maize (Zea mays L.) is known as golden crop because every part of this crop is useful to man, animals and the industries. Globally, it is the most important cereal food crop after wheat and rice accounting for 9 per cent of the total food grain production. It has occupied a prominent place in Indian agriculture as it is widely grown in India in varied climatic situations throughout the year suggesting its wider adaptability.

The major objective of the maize breeding programmes is to develop high yielding hybrids than the existing cultivars as hybrids are popular among the farming community for their yield advantage over the varieties and others. To develop high yielding hybrids in maize, the development and evaluation of inbreds form the major thrust area of the plant breeding programmes. Hence, inbred lines developed through sib mating etc. need to be evaluated for their genetic diversity and 
performance to plan an effective hybrid breeding programme as genetically diverse parents are known to produce high heterotic effects.

Evaluation, characterization and classification of genotypes based on estimates of genetic diversity will help to identify diverse parental lines which can be used in hybrid breeding to develop potential hybrids or varieties. Several methods have been reported to decipher the pattern and magnitude of variability such as Mahalanobis $\mathrm{D}^{2}$ analysis, Principal component analysis and hierarchical cluster analysis based on Ward's minimum variance method. PCA and cluster analysis is better utilized for studying the diversity among the genotypes in various crops, In view of the above, 47 inbred lines were investigated to study the nature and magnitude of genetic divergence for grain yield and its component characters to provide a basis for selection of parents in hybridization programme in Maize hybridization programme.

\section{Materials and Methods}

\section{Experimental material}

The present investigation was carried out during rabi, 2016-17 at Agricultural college farm, Bapatla, Guntur district using 47 maize inbred lines obtained from IARI Regional Maize Research Center, Dharwad, Karnataka in a Randomized Block Design with three replications. Each entry was sown in two rows of $3 \mathrm{~m}$ length maintaining a spacing of $60 \mathrm{~cm} \times 30 \mathrm{~cm}$. Standard agronomic management practices were followed throughout the growing period to maintain proper plant stand and good crop growth. The observations were recorded on ten randomly selected plants for seven quantitative characters viz., plant height, ear length, ear height, 100-seed weight, kernel rows per ear, number of kernels per row and grain yield per plant. The data on remaining quantitative characters viz., days to $50 \%$ tasseling, days to $50 \%$ silking and days to maturity were recorded on plot basis. The mean values of the data were used for statistical analysis.

\section{Statistical analysis}

The data was analyzed for Principal component analysis (PCA) for dimensional reduction and to know the importance of different traits in explaining multivariate polymorphism. Hierarchical cluster analysis was done following the minimum variance method of Ward (1963) based on squared Euclidean distances.

\section{Results and Discussion}

The analysis of variance for 47 inbred lines of Maize for ten quantitative traits showed significant differences between the inbred lines for the characters studied indicating a considerable amount of genetic variability in the studied material and the utility of divergence analysis in the present material for identification of divergent groups.

In principal component (PC) analysis, the number of variables was reduced to linear functions called canonical vectors which accounted for most of the variation produced by the characters under study. The eigen values, per cent variance, per cent cumulative variance and factor loading of different characters studied are presented in Table 1. In this experiment, first four principal components (PC) based on 10 quantitative traits showed eigen values greater than 1 . The contribution of these four PCs was $80.35 \%$ in the overall variability among the genotypes. The contribution of $\mathrm{PC} 1$ was found to be $28.95 \%$ in the total divergence of the studied population, in which the major contributing traits were days to $50 \%$ tasseling, days to $50 \%$ silking, days to maturity, ear height, plant 
height, 100-seed weight, ear length, grain yield per plant and number of kernels per row. The second principal component (PC2) was responsible for about $25.16 \%$ of the variation and was mainly contributed by days to maturity, days to $50 \%$ silking and days to $50 \%$ tasseling. The third principal component (PC3) explained $13.96 \%$ of variation and was associated mainly with grain yield per plant, kernel rows per ear, days to $50 \%$ tasseling, days to $50 \%$ silking and days to maturity. The fourth principal component (PC4) explained $12.28 \%$ variation and was contributed by number of kernels per row, grain yield per plant, kernel rows per ear, days to maturity, days to $50 \%$ tasseling and days to $50 \%$ silking.
Cluster analysis based on PCA scores were compared with the results of the principal component analysis on a visual aid in desecrating clusters in the two dimensional scattered diagram and the genotypes falling in same cluster were present closer to each other in the scattered diagram.

Two dimensional scatter diagram was shown in Figures 1, and the genotypes numbered 41 and 36 i.e., CDM-306 and CDM-320 scattered away from other genotypes.

These results were in accordance with those of Jinju et al., (2009), Muhammad et al., (2012), Sandeep et al., (2015), Avinash and Mishra (2016) and Shrestha (2016) in maize.

Fig.1 Two dimensional graph showing relative position of 47 maize (Zea mays L.) genotypes based on PCA scores

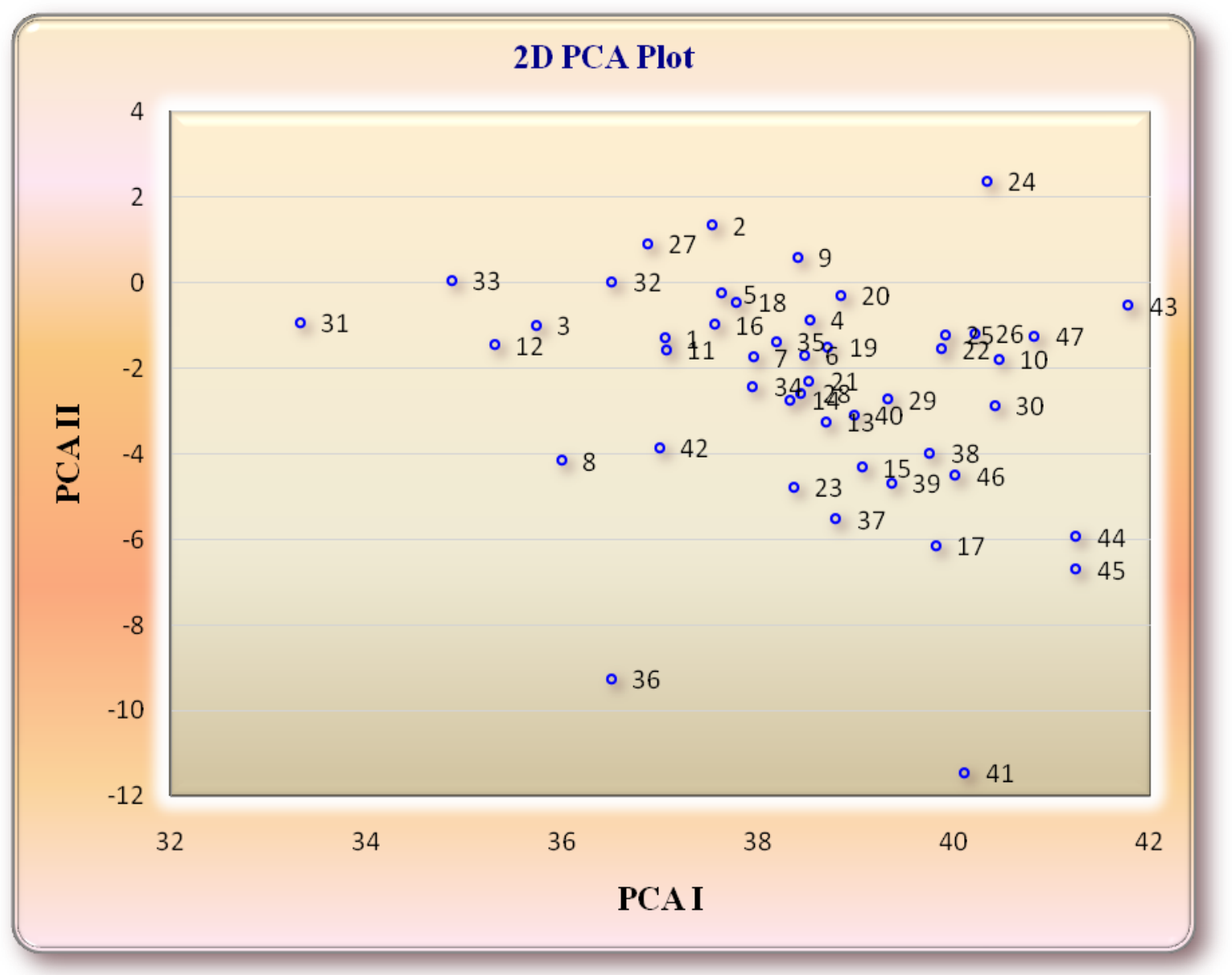


Fig.2 Dendrogram showing relationship of 47 maize (Zea mays L.) inbreds in seven clusters based on Euclidean ${ }^{2}$ distance

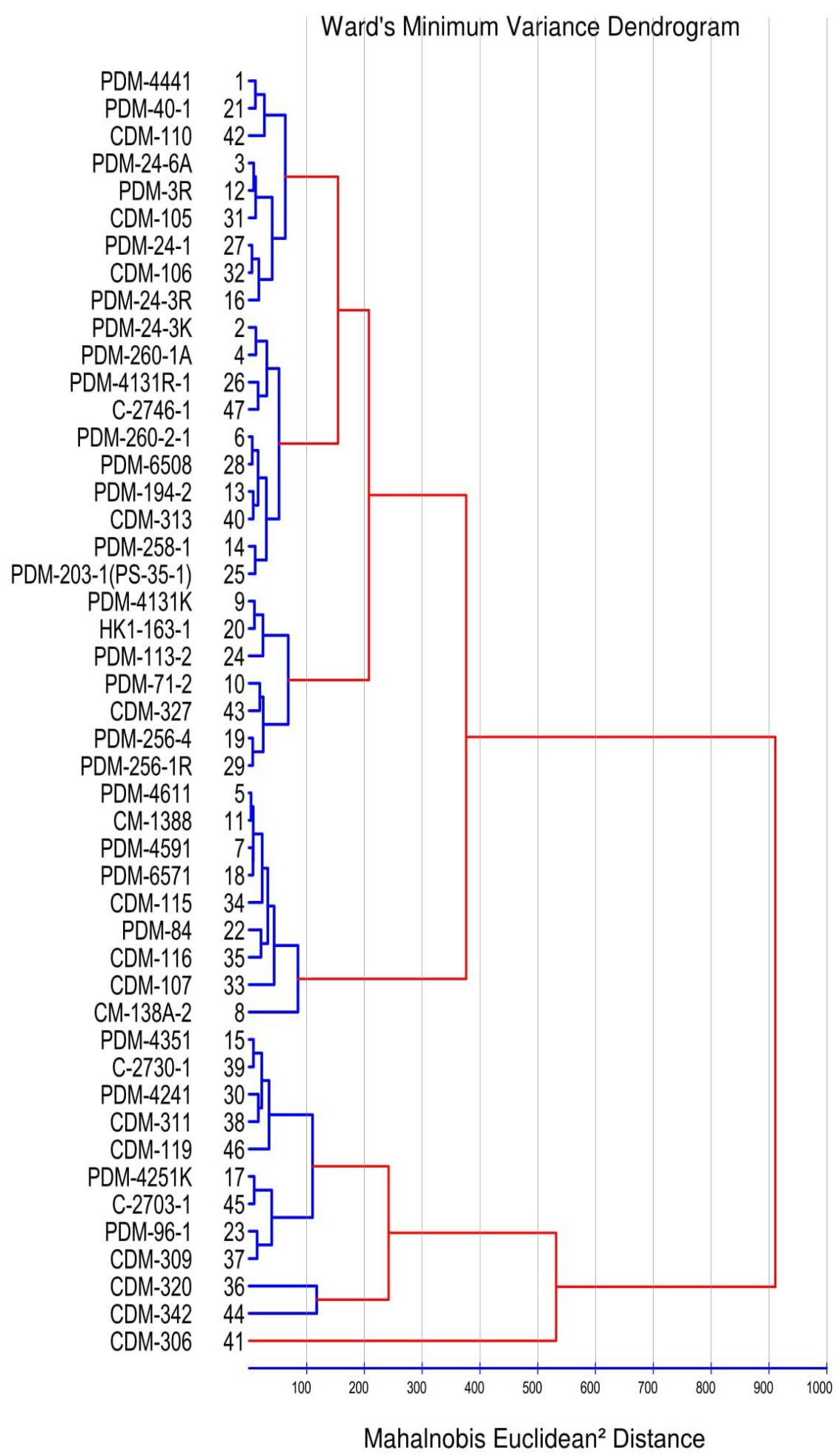


Fig.3 Intra and inter-cluster distance of 47 maize (Zea mays L.) inbreds in seven clusters based on Euclidean ${ }^{2}$ values

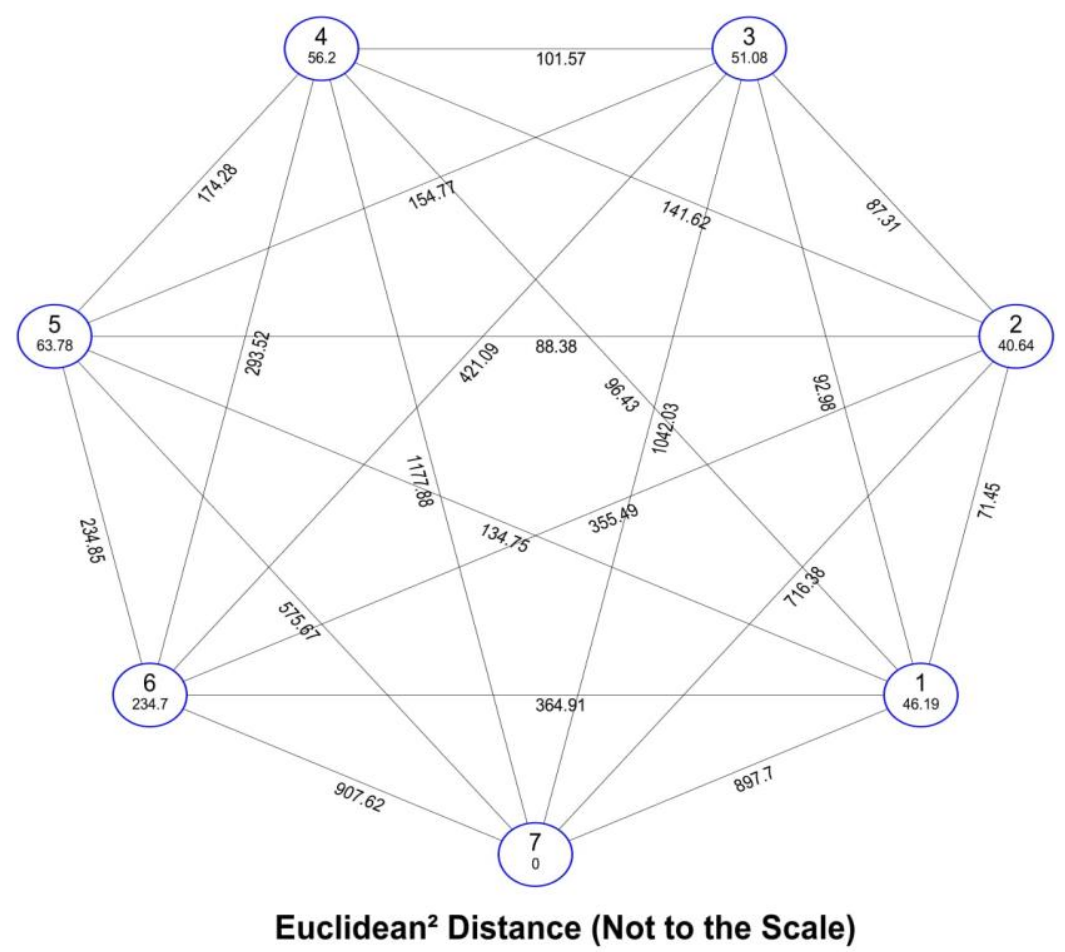

Table.1 Eigen values, proportion of the total variance represented by first four Principal components, cumulative per cent variance and component loading of different characters in maize (Zea mays L.)

\begin{tabular}{|l|l|l|l|l|}
\hline & PCA $_{1}$ & PCA $_{2}$ & PCA $_{3}$ & PCA $_{4}$ \\
\hline Eigen Value (Root) & $\mathbf{2 . 8 9}$ & $\mathbf{2 . 5 2}$ & $\mathbf{1 . 4 0}$ & $\mathbf{1 . 2 3}$ \\
\hline \% Var. Exp. & $\mathbf{2 8 . 9 5}$ & $\mathbf{2 5 . 1 6}$ & $\mathbf{1 3 . 9 6}$ & $\mathbf{1 2 . 2 8}$ \\
\hline Cum. Var. Exp. & $\mathbf{2 8 . 9 5}$ & $\mathbf{5 4 . 1 0}$ & $\mathbf{6 8 . 0 7}$ & $\mathbf{8 0 . 3 5}$ \\
\hline Days to 50\% tasseling & 0.55 & 0.11 & 0.04 & 0.09 \\
\hline Days to 50\% silking & 0.55 & 0.13 & 0.03 & 0.07 \\
\hline Days to maturity & 0.52 & 0.16 & 0.13 & 0.13 \\
\hline Plant height & 0.21 & -0.40 & -0.29 & -0.37 \\
\hline Ear length & 0.07 & -0.17 & -0.13 & -0.27 \\
\hline Ear height & 0.22 & -0.43 & -0.37 & -0.27 \\
\hline 100-seed weight & 0.08 & -0.19 & -0.71 & -0.30 \\
\hline Kernel rows per ear & -0.10 & -0.44 & 0.21 & 0.16 \\
\hline Number of kernels per row & 0.04 & -0.28 & -0.27 & 0.70 \\
\hline Grain yield per plant & 0.07 & -0.51 & 0.36 & 0.28 \\
\hline PC = Principal component & & & & \\
\hline
\end{tabular}


Table.2 Clustering pattern of 47 maize (Zea mays L.) inbreds by

Ward's minimum variance method

\begin{tabular}{|c|c|c|}
\hline Cluster No & No. of inbreds & Names of inbreds \\
\hline I & 9 & $\begin{array}{l}\text { PDM-4441, PDM-40-1, CDM-110, PDM-24-6A, PDM-3R, } \\
\text { CDM-105, PDM-24-1, CDM-106, PDM-24-3R }\end{array}$ \\
\hline II & 10 & $\begin{array}{l}\text { PDM-24-3K, PDM-260-1A, PDM-4131R-1, C-2746-1, } \\
\text { PDM-260-2-1, PDM-6508, PDM-194-2, CDM-313, PDM- } \\
\text { 258-1, PDM-203-1(PS-35-1) }\end{array}$ \\
\hline III & 7 & $\begin{array}{l}\text { PDM-4131K, HK1-163-1, PDM-113-2, PDM-71-2, CDM- } \\
\text { 327, PDM-256-4, PDM-256-1R }\end{array}$ \\
\hline $\mathbf{I V}$ & 9 & $\begin{array}{l}\text { PDM-4611, CM-1388, PDM-4591, PDM-6571, CDM-115, } \\
\text { PDM-84, CDM-116, CDM-107, CM-138A-2 }\end{array}$ \\
\hline $\mathbf{V}$ & 9 & $\begin{array}{l}\text { PDM-4351, C-2730-1, PDM-4241, CDM-311, CDM-119, } \\
\text { PDM-4251K, C-2703-1, PDM-96-1, CDM-309 }\end{array}$ \\
\hline VI & 2 & CDM-320, CDM-342 \\
\hline VII & 1 & CDM-306 \\
\hline
\end{tabular}

Table.3 Average intra and inter-cluster Euclidean ${ }^{2}$ values among seven clusters in 47 maize (Zea mays L.) inbreds

\begin{tabular}{|l|l|l|l|l|l|l|l|}
\hline Cluster No. & I & II & III & IV & V & VI & VII \\
\hline I & $\mathbf{4 6 . 1 9}$ & 71.45 & 92.98 & 96.43 & 134.75 & 364.91 & 897.70 \\
\hline II & & $\mathbf{4 0 . 6 4}$ & 87.31 & 141.62 & 88.34 & 355.49 & 716.38 \\
\hline III & & & $\mathbf{5 1 . 0 8}$ & 101.57 & 154.78 & 421.09 & 1042.03 \\
\hline IV & & & $\mathbf{5 6 . 2 0}$ & 174.28 & 293.51 & 1177.88 \\
\hline V & & & & $\mathbf{1 7 4 . 2 8}$ & 293.85 & 575.70 \\
\hline VI & & & & & $\mathbf{2 3 4 . 7 0}$ & 907.62 \\
\hline VII & & & & & & $\mathbf{0 . 0 0}$ \\
\hline
\end{tabular}

Note: Diagonal values are intra-cluster distances. Off-diagonal values are inter-cluster distances

Table.4 The nearest and the farthest cluster from each cluster using Ward's Minimum Variance method in 47 inbreds of maize (Zea mays L.)

\begin{tabular}{|l|c|c|}
\hline Cluster No. & Nearest cluster with D $^{2}$ values & Farthest cluster with D2 values \\
\hline I & II (71.45) & VII (897.70) \\
\hline II & I (71.45) & VII (716.38) \\
\hline III & II (87.31) & VII (1042.03) \\
\hline IV & I (96.43) & VII (1177.88) \\
\hline V & II (88.34) & VII (575.70) \\
\hline VI & IV (293.51) & VII (907.62) \\
\hline VII & V (575.70) & IV $(1177.88)$ \\
\hline
\end{tabular}


Table.5 Mean values of seven clusters estimated by Ward's minimum variance method from 47 maize (Zea mays L.) inbreds

\begin{tabular}{|c|c|c|c|c|c|c|c|c|c|c|}
\hline $\begin{array}{l}\text { Cluster } \\
\text { No. }\end{array}$ & $\begin{array}{l}\text { Days } \\
\text { to } 50 \% \\
\text { tasseling }\end{array}$ & $\begin{array}{l}\text { Days } \\
\text { to } 50 \% \\
\text { silking }\end{array}$ & $\begin{array}{l}\text { Days to } \\
\text { maturity }\end{array}$ & $\begin{array}{l}\text { Plant height } \\
\text { (cm) }\end{array}$ & $\begin{array}{l}\text { Ear } \\
\text { length } \\
(\mathrm{cm})\end{array}$ & $\begin{array}{l}\text { Ear } \\
\text { height } \\
(\mathrm{cm})\end{array}$ & $\begin{array}{l}100 \\
\text { seed } \\
\text { weight } \\
\text { (g) }\end{array}$ & $\begin{array}{l}\text { Kernel } \\
\text { rows } \\
\text { per ear }\end{array}$ & $\begin{array}{l}\text { No. of } \\
\text { kernels } \\
\text { per row }\end{array}$ & $\begin{array}{l}\text { Grain } \\
\text { yield per } \\
\text { plant } \\
\text { (g) }\end{array}$ \\
\hline I & 53.63 & 59.96 & 90.96 & 141.75 & 17.71 & 50.01 & 18.32 & 12.74 & 19.71 & 58.28 \\
\hline II & 56.87 & 63.50 & 99.47 & 140.27 & 20.80 & 47.65 & 20.58 & 13.45 & 21.46 & 71.57 \\
\hline III & 58.14 & 64.67 & 100.43 & 168.55 & 20.20 & 61.09 & 18.36 & 13.18 & 17.66 & 50.20 \\
\hline IV & 55.15 & 61.33 & 94.33 & 156.56 & 20.02 & 59.13 & 14.17 & 13.42 & 22.76 & 56.21 \\
\hline$\overline{\mathbf{V}}$ & 57.00 & 63.63 & 97.49 & 173.99 & 21.22 & 64.31 & 20.85 & 14.69 & 25.82 & 94.93 \\
\hline VI & 55.17 & 61.33 & 94.50 & 184.37 & 21.38 & 74.63 & 16.30 & 14.27 & 45.21 & 103.61 \\
\hline VII & 56.33 & 61.33 & 96.00 & 182.27 & 17.13 & 66.40 & 34.78 & 17.87 & 27.27 & 170.96 \\
\hline
\end{tabular}


The principal component scores of genotypes were used as input for cluster analysis using Euclidean $^{2}$ distances in order to group the genotypes into various clusters and to confirm the results of principal component analysis. Forty seven genotypes were grouped into seven clusters using the Ward's minimum variance procedure (Anderberg, 1993) and the distributions of the genotypes into different clusters are depicted in Table 2 and Figure 3. Among all the clusters, cluster II was the largest containing ten genotypes followed by clusters I, IV, and V containing nine genotypes in each cluster, cluster III with seven genotypes, cluster VI with two genotypes and cluster VII was monogenotypic having only one genotype. The mutual relationship between clusters is represented diagrammatically in Figure 4 by taking average intra and inter-cluster Euclidean ${ }^{2}$ distances. The average intra and inter-cluster Euclidean $^{2}$ distance were estimated based on Ward's minimum variance and are presented in the Table 3. Similar results of clustering were reported by Mehrnaz et al., (2014), Hafiz et al., (2015), Muhammad et al., (2015) and Sandeep et al., (2015).

The nearest and farthest cluster for each of the seven clusters are presented in Table 4 . The cluster VII was solitary with intra-cluster distance zero. Cluster II had minimum intracluster Euclidean ${ }^{2}$ distance value of 40.64 followed by cluster I (46.19), cluster III (51.08), cluster IV (56.20), cluster V (174.28) and maximum was recorded in the cluster VI (234.70). The maximum inter-cluster distance was observed between clusters IV and VII (1177.88) followed by clusters III and VII (1042.03) and clusters VI and VII (907.62) suggesting wide genetic diversity between these clusters and can be exploited for traits improvement in the breeding programmes.

Cluster means were computed for the 10 characters studied by Ward's minimum variance method and are presented in Table 5. Out of all the clusters, cluster VI showed higher mean values for most of the yield contributing traits like plant height, ear length, ear height and number of kernels per row indicating the importance of this cluster genotypes in maize yield improvement programmes.

Based on inter-cluster distances and per se performance of the genotypes included in the farthest clusters, genotypes viz., CDM-306, CDM-320, CDM-342 AND CM-138A-2 are showing maximum inter cluster distance and good per se performance. Hence, they can be included in crossing programmes for generating heterotic hybrids for various yield traits in maize.

\section{Acknowledgements}

The authors are highly grateful to the Dr. Jayanth S. Bhat, IARI Regional Research Station, Dharwad for providing the material and the first author acknowledge the receipt of financial help in the form stipend from Acharya N G Ranga Agricultural University, Guntur, Andhra Pradesh during the Degree programme.

\section{References}

Anderberg, M.R. 1993. Cluster Analysis for Application. Academic Press, New York.

Avinash, J and Mishra, D.K. 2016. Genetic studies of elite landraces of maize based on divergence for yield and its components. Environment and Ecology. 34(3): 858-862.

Hafiz, S.B.M., Jehanzeb, F., Ejaz-ul-Hasan., Tahira, B and Mahmood, T. 2015. Cluster and principle component analyses of maize accessions under normal and water stress conditions. 
Journal of Agricultural Sciences. 60 (1): 33-48.

Jinju, H., Xiang, Z.C., Rouyi, C., Fabo, C and Fahui, C. 2009. Analysis on principal components of maize cross combinations in Guizhou. Guizhou Agricultural Sciences. 8: 4-6.

Mehrnaz, T., Elham, B., Ali, R, A and Ali, R.A.K. 2014. Genetic diversity of 13 maize (Zea mays L.) hybrids based on multivariate analysis methods. International Journal of Farming and Allied Sciences. 3 (5): 467-470.

Muhammad, R.W., Qayyum, A., Hamza, A., Ahmad, M.Q., Naseer, N.S., Liaqat, S., Ahmad, B., Malik, W and Noor, E. 2015. Analysis of genetic traits for drought tolerance in maize. Genetics and Molecular Research. 28: 14(4): 13545-65.

Muhammad, R.W., Rukhsana, A., Shoib, L., Abdul, Q., Waqas, M., Naveed, M., Mumtaz, H., Jahangir, S., Khan, S. M., Bashir, A., Rao, S. A and Etrat, N. 2012. Numerical evaluation of local and exotic maize genotypes in arid conditions. Journal of Food Agriculture and Environment. 10 (1): 624-630.

Sandeep, S., Bharathi, M., Narsimha, R.V and Eshwari, K.B. 2015. Principal component analysis in inbreds of Maize (Zea mays L.). International Journal of Tropical Agriculture. 33(2): 213-216.

Shrestha, J. 2016. Cluster Analysis of Maize inbred lines. Journal of Nepal Agricultural Research Council. 2: 3336.

\section{How to cite this article:}

Mounika K., M. Lal Ahamed and Nafeez Umar Sk. 2018. Principal Component and Cluster Analysis in Inbred Lines of Maize (Zea mays L.). Int.J.Curr.Microbiol.App.Sci. 7(06): 32213229. doi: https://doi.org/10.20546/ijcmas.2018.706.379 